\section{Relações entre profissionalismo e política nas carreiras jurídicas}

Maria da Glória BONELLI. Profissionalismo e politica no mundo do direito. São Carlos, Sumaré/Edufscar/Fapesp, 2002. 303 páginas.

Cátia Aida Silva

Entre as recentes pesquisas da área de ciências sociais que vêm revelando o funcionamento das instituições e os perfis dos profissionais do direito no Brasil, o livro de Maria da Glória Bonelli certamente desponta como leitura de grande relevância. O livro analisa, de forma inovadora, o modo pelo qual as carreiras de advogados, desembargadores, procuradores de justiça e delegados de polícia interagiram com os modelos do profissionalismo, do mercado livre e da burocracia, aproximando-se ou distanciando-se da construção de uma ideologia profissional. O ethos profissional acentuaria o compromisso de ter exclusividade no exercício de determinada função e a condição de autonomia para exercê-la, diferenciando-se do modelo de livre-mercado - que enfatizaria a lógica das relações entre classes - e do modelo burocrático - baseado na hierarquia e na obediência. A dimensão política está presente na análise, uma vez que a interação das carreiras com esses modelos é considerada fruto das relações construídas com o Estado e com a política convencional. Adotando uma perspectiva históri$\mathrm{ca}$, Bonelli recorreu ao exame da morfologia social de determinados grupos dentro dessas carreiras, assim como à realização de uma pesquisa que incluiu entrevistas e análise de survey, de publicações especializadas, de discursos e de memórias.

Entre os advogados, Bonelli mostra como a ideologia profissional produzida no âmbito do Instituto dos Advogados do Brasil (IAB) e, em seguida, da Ordem dos Advogados do Brasil (OAB) conseguiu fazer frente à lógica do mercado e da política convencional. Enquanto o IAB despontou como uma associação de uma elite portadora da excelência profissional, a $\mathrm{OAB}$ assumiu o papel de associação de uma grande massa de profissionais, mantendo-se ao longo do processo de democratização do país como porta-voz da opinião pública e posicionando-se com autonomia ante o Estado.

Quanto ao Poder Judiciário, a autora dirige seu olhar para os desembargadores do Estado de São Paulo. Ao analisar o Judiciário paulista, a autora demarca suas diferenças em relação à literatura existente: primeiro, ante as vertentes que se pautam nos estudos sobre elites políticas, ou apontando a diferença dos juízes em relação às demais elites ou enfatizando os interesses de classe dos mesmos; segundo, ante a abordagem que vê a crescente heterogeneidade social dos juízes como fonte de rupturas ideológicas no Poder Judiciário. Em relação aos primeiros enfoques, Bonelli argumenta que os conceitos de burocracia e profissão são utilizados como sinônimos quando representariam, na verdade, formas distintas de organização do trabalho. Bonelli argumenta que o profissionalismo conseguiu aos poucos suplantar a burocracia e que o modelo profissional resultante dos "embates" no Judiciário privilegiou o $\mathrm{Co}-$ nhecimento técnico e domínio da jurisprudência sem abrir mão de "influenciar a política": "Sua habilidade foi distinguir-se dos interesses particulares que caracterizam a política cotidiana, construindo um ideário voltado para o conhecimento especializado e para valores reconhecidos como universais" (p. 93).

Quanto à vertente que destaca a crescente heterogeneidade da origem social da corporação, que levaria a uma pluralidade de orientações e quebra da tradição normativista, Bonelli sustenta que heterogeneidade ideológica não é um processo que resulta automaticamente da existência de heterogeneidade social. Segundo a autora, a origem social semelhante que marcou o passado não impediu a existência de diversas ideologias profissionais e que as disputas entre elas no mundo do direito persistem ainda hoje pelo fato de serem profissões muito próximas à política e ao Estado.

Entretanto, como a própria autora reconhece, seu estudo restringe-se à analise do Judiciário paulista, em particular os desembargadores do Tribunal de Justiça do Estado de São Paulo, cujas publicações e fontes pesquisadas (Revista dos Tribu- 
nais, Revista de Jurisprudência e memória de juízes) favorecem a leitura da visão dos grupos dominantes e, no interior da instituição paulista, dos membros da segunda instância. Os títulos e autores citados como representantes dos enfoques acima - como o estudo de Luis Werneck Vianna e equipe, por exemplo, voltam-se para os membros da primeira instância, e não apenas no Estado de São Paulo. Além disso, não têm como foco a discussão sobre o profissionalismo. De qualquer maneira, insinua-se aí um importante debate a ser aprofundado em pesquisas futuras, que ainda têm muito por dizer sobre o "mundo do direito", para empregar a expressão da própria autora.

Em relação aos procuradores de justiça do Ministério Público paulista, Bonelli identifica os anos de 1980 como um momento de transformações na composição social e "ideário" dos procuradores em direção a mudanças na instituição e a valores profissionais próximos aos magistrados. As mudanças no perfil da instituição teriam gerado condições para o fortalecimento de uma ideologia profissional que rejeita a política, sobretudo a convencional. A autora conclui que, entre os procuradores de justiça, predomina a ideologia profissional que procura distanciar-se da política, contrária a uma ideologia minoritária, que questiona a profissão como antipolítica.

Muitos estudos mostram que as mudanças em relação à maneira pela qual a carreira é percebida e exercida pelos membros do Ministério Público paulista e de outros Estados tiveram origem nas transformações legais e institucionais que, ao longo dos anos de 1980 e 1990, procuraram igualar juízes e promotores de justiça, dando aos últimos atribuições importantíssimas. Nesse sentido, o terceiro capítulo do livro pode ser analisado como um resgate dos bastidores da mobilização da instituição paulista durante a Constituinte e sua força na redação de um novo capítulo para o Ministério Público no Brasil. Há que se ressaltar que a diferença entre Poder Judiciário e Ministério Público reside no fato de que, no Ministério Público, as disputas por ideologias profissionais ou pela redefinição da carreira no interior do "mundo do direito" ocorriam num contexto de reconstrução da instituição, a qual assu- miu o papel de portadora dos interesses da sociedade e dos cidadãos. O mais curioso é que o recurso à política convencional foi o meio utilizado para se alcançar esse novo status, o que possibilitou, paradoxalmente, o florescimento de uma ideologia que condena de forma veemente essa mesma política.

Reiterando, o estudo de Bonelli restringe-se aos membros da segunda instância do Ministério Público e identifica nesse contexto duas ideologias em permanente confronto. Contudo, arriscaria a dizer que, talvez, entre os promotores de justiça (membros que atuam na primeira instância), as ideologias a respeito da carreira estabelecem uma relação estreita com a área na qual atuam. Por exemplo, os promotores da área criminal encarariam a carreira de modo completamente distinto daquele dos promotores da área de defesa do meio ambiente. Ademais, parece florescer entre eles uma ideologia que condena a política convencional, mas que não se caracteriza como antipolítica, pois valoriza os efeitos políticos do papel da instituição e, por isso mesmo, apresenta o promotor e o procurador de justiça como agentes intocáveis a combater autoridades corruptas e a defender os interesses dos cidadãos pobres, dos que foram lesados, das minorias etc.

Por fim, o quarto capítulo trata da carreira dos delegados de polícia. Bonelli mostra que os delegados experimentaram um processo de deslegitimação ante juízes, promotores e advogados. O mesmo ocorreu em relação à população, uma vez que foram inevitavelmente associados à imagem corrupta e incompetente da polícia. A autora vê ambigüidade da corporação quanto ao ethos profissional, já que a política convencional sempre teria predominado entre os delegados. Segundo Bonelli, a política convencional contraria a "crença na missão de prestar serviços de qualidade com independência”, opondo-se, nesse sentido, à ideologia profissional, uma vez que a profissão procura resguardar-se dos seus efeitos nocivos, criando uma política própria. Assim, perda de prestígio social, politização do cargo, preocupação dos governantes em controlar a polícia e baixa identificação com a expertise (mérito, conhecimento científico, opinião dos pares, exclusividade 
sobre determinada função) atuaram como impedimentos à profissionalização, favorecendo a predominância da política convencional. Os delegados são, portanto, os mais distantes da ideologia profissional e, não por acaso, trata-se, de todas as carreiras jurídicas analisadas, de menor status social e menor poder aquisitivo. A falta de legitimidade dificulta, segundo Bonelli, assumir a "autoridade técnica" com "mandato moral".

Em contrapartida, a autora sustenta que a análise dos dados de um survey realizado entre os delegados revela uma momento de importantes mudanças. As respostas mostram o desconforto dos delegados com o peso da política convencional que incide sobre sua carreira. O survey mostra também a valorização do profissionalismo pelos delegados, certamente associada à preocupação dos membros dessa carreira com a legitimidade da autoridade policial - daí a importância atribuída por eles à prestação de serviços à comunidade. Além disso, as respostas dos delegados parecem indicar que, pelo menos em relação à autopercepção, houve mudanças, mas resta saber de que forma isso se reflete na sua atuação profissional. Mudanças mais profundas, de qualquer modo, enfrentariam resistências não só de membros da carreira, como também da própria estrutura da Polícia Civil - organização burocrática com mescla de profissionalismo, como aponta a autora.

\section{Cátia Aida Silva é doutora em Ciência Política pela Universidade de São Paulo.}

\section{Encontros e desencontros da sociologia e educação no Brasil}

Graziella Moraes DIAS DA SILVA. Sociologia da sociologia da educação: caminhos e desafios de uma policy science no Brasil (1920-1979). Bragança Paulista, Editora da Universidade São Francisco. 203 páginas

\section{Carlos Benedito Martins}

Após uma fase de acentuado recuo no interior das ciências sociais brasileira, assiste-se a partir da década de 1980 a retomada de uma reflexão sistemática e da realização metódica de trabalhos teóricos e empíricos sobre o tema da educação e de sua articulação com outros campos sociais. Em recente publicação da Anpocs O que ler na ciência social brasileira (1970-2002), Clarissa Baeta Neves, ao realizar um balanço crítico do estágio atual dos estudos sociológicos sobre educação no Brasil, destacou não só o seu significativo volume, mas também uma riqueza de linhas de pesquisa e uma pluralidade de enfoques analíticos, bem como a existência de diversos grupos de pesquisa dedicados a essa temática, a maioria deles, em estreita conexão com os programas de pós-graduação em sociologia, localizados em várias regiões do país. O trabalho de Graziella Silva é uma contribuição relevante para resgatar determinados momentos dos caminhos e dos descaminhos percorridos pelas afinidades estabelecidas entre a sociologia e a educação no país. Uma das motivações que orientaram sua realização foi entender as condições que conduziram o desinteresse da sociologia brasileira pela temática da educação, de modo destacado durante o período que se estende do golpe militar até o início do processo de redemocratização do país. Esse desinteresse não deixa de ser intrigante, quando se tem em conta a própria origem da sociologia no Brasil, a qual, na visão da autora, nasceu em estreita relação com a temática educacional.

Ao longo do trabalho, Graziella esboça os contornos históricos e institucionais que permea- 